\title{
A NOVA POLÍTICA PÚBLICA DE EDUCAÇÃO E FORMAÇÃO DE ADULTOS EM PORTUGAL. OS EDUCADORES DE ADULTOS NUMA ENCRUZILHADA?
}

\author{
Paula Guimarâes* \\ ROSANNA BARROS $^{* *}$
}

\begin{abstract}
RESUMO: Neste artigo leva-se a cabo uma breve análise da nova política pública de educação de adultos adotada em Portugal após 1999. Esta discussão baseia-se em elementos de cariz político e educativo, em particular nos perfis dos educadores de adultos, de acordo com três modelos de políticas públicas. $\mathrm{O}$ artigo inclui a análise de dados empíricos recolhidos no âmbito de dois projetos de investigação, através de entrevistas semi-estruturadas e abertas, assim como observaçáo direta do trabalho realizado por educadores de adultos. Estes dados foram objeto da análise de conteúdo. As consideraçôes finais destacam as tensões inerentes ao trabalho realizado pelos educadores de adultos.
\end{abstract}

Palavras-chave: Política pública; Educação de adultos; Educadores de adultos.

\section{THE NEW PUBLIC POLICY FOR ADULT EDUCATION AND TRAINING POLICY IN PORTUGal. ARE ADULT EDUCATORS AT A CROSSROAD?}

ABSTRACT: A brief analysis of the new adult education public policy adopted in Portugal after 1999 is made in this article. This discussion is based on elements which have an educational and political nature, more specifically, on the professional profiles of adult educators, according to three public educational policy models. This article discusses empirical data collected in two research projects, by means of semi-structured and open interviews, as well as direct observation of the work carried out by adult educators in their workplaces. These data were the object of content analysis. Final considerations stress the tensions inherent to the work conducted by these practitioners.

Keywords: Public policy; Adult education; Adult educators.

\footnotetext{
* Universidade de Lisboa, Instituto de Educaçáo, Lisboa, Portugal. E-mail de contato: pguimarães@ie.ul.pt.

** Universidade do Algarve, Escola Superior de Educação e Comunicação, Faro, Portugal. E-mail de contato: rmbarros@ualg.pt.
} 


\title{
LA NOUVELLE POLITIQUE D'ÉDUCATION ET DE FORMATION DES ADULTES AU PORTUGAL. LES FORMATEURS D'ADULTES À LA CROISÉE DES CHEMINS?
}

\begin{abstract}
RÉSUMÉ: Cet article s'intéresse à la nouvelle politique publique d'éducation et de formation d'adultes adoptée au Portugal depuis 1999 et plus particulièrement, à trois profils de formateurs d'adultes prenant pour base trois modèles de politique publique. Il propose une analyse des données empiriques recueillies dans le cadre de deux projets de recherche, par des entretiens semi-directifs et ouverts d'une part; l'observation directe du travail réalisé par les formateurs d'adultes, d'autre part. Ces données ont fait l'objet d'une analyse de contenu. Les considérations finales font apparaitre les tensions inhérentes à l'exercice du métier de formateur d'adultes qui se situe depuis 1999 à la croisée des chemins dont nous ne rendons compte ici, que des principaux traits.
\end{abstract}

Mots-clés: Politique publique; Éducation d'adultes; Formateurs d'adultes.

\section{Os educadores de adultos no quadro das políticas públicas}

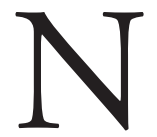

a decorrência dos trabalhos levados a cabo, por exemplo, por Rothes (2003), Cavaco (2009) e Loureiro, 2009, surgiram análises sobre aspetos de natureza sociográfica relativos aos educadores de adultos, sobre os seus percursos de formação inicial, bem como sobre as tarefas por estes levadas a cabo que não deixaram de apontar problemas com os quais aqueles agentes se confrontavam. Complementarmente, este debate tem estado ligado às orientações para a educação inerentes às políticas públicas adoptadas (em particular de educação de base), e ao papel desempenhado por estes sujeitos no âmbito de programas que se suportavam em conceçóes de educação de adultos muito distintas. (BARROS, 2013a; 2013b; entre outros)

Um breve olhar sobre a história recente das políticas públicas de educação de adultos em Portugal pode favorecer a discussão das oportunidades e dos dilemas vividos pelos educadores de adultos ao longo dos últimos 40 anos. Assim, após o 25 de Abril de 1974, aquando da Revolução Democrática, e até meados da década de 1980, a educação de adultos apoiou-se em políticas de educação crítica. (LIMA, 2008; GUIMARÁES, 2011) Visando a promoção da justiça social, através de mudanças relevantes nas condiçôes de vida das pessoas, a política promovida pela Direção-Geral de Educação Permanente entre 1974 e 1976 procurou uma mudança radical no modo como se pensava a educação, num país cuja população total residente era então de 8.663.252 indivíduos, segundo o XI Recenseamento Geral da População de 1970 (Disponível em: <http://censos.ine.pt>), sendo 
hoje de 10.427.301 (Disponível em: <http://www.ine.pt>). Esta política surgiu de negociaçóes entre o Estado e a sociedade civil, designadamente as associaçóes populares, relativamente a objetivos, estratégias, ofertas, administração e gestão das organizaçôes de educação de adultos. A educação popular então dinamizada destinou-se a favorecer participação de largos sectores da população, num momento em que aproximadamente 25\% dos indivíduos eram analfabetos (Disponível em: <http://www.ine.ine.pt>). As atividades levadas a cabo dirigiam-se para a promoçáo da reflexão crítica e emancipatória. Emergiram, então, educadores de adultos comprometidos com os projetos e as atividades educativas implementados pelas comunidades locais que tinham vivido cinco décadas de regime autoritário. (MELO; BENAVENTE, 1978)

Mais tarde, no âmbito do Plano Nacional de Alfabetização e Educação de Base de Adultos, adotado em 1979 (mesmo que abandonado em meados da década de 1980), foram igualmente agentes com um perfil muito aproximado ao dos educadores populares que procuraram promover a alfabetização crítica, animar as comunidades locais, formar os adultos para novas realidades profissionais e de trabalho e dinamizar ações de educação não formal muito diversas. (MINISTÉRIO DA EDUCAÇÃO, 1979)

Em 1986 Portugal aderiu à Comunidade Económica Europeia (CEE), reconvertida em União Europeia (UE) a partir de 1992. Nesse mesmo ano, foi aprovada a Lei de Bases do Sistema Educativo (Lei n. 46/86, de 14 de Outubro). Neste contexto, as políticas de educação para o controle e conformidade social tornaram-se mais evidentes. (LIMA, 2008; GUIMARÃES, 2011) Nestas, o Estado apresentou-se como o ator principal, responsável pela definição de objetivos, estratégias, ofertas, regras de administração e gestão das organizaçôes educativas, sobretudo de cariz formal. Os discursos políticos destacaram a educação de segunda oportunidade. Enfatizaram a aquisição de conhecimentos e capacidades necessários para o desenvolvimento económico, no contexto da modernização económica e social e da globalização. A educação básica apresentou-se também como uma prioridade no âmbito de programas que procuravam a concretização do direito à educação e à justiça social. Em resultado, assistiu-se a uma profunda normalização e formalização do trabalho pedagógico e das práticas educativas que envolviam adultos. Ao invés dos educadores ativistas que se tinham envolvido em inúmeras ações educativas no pós- 25 de Abril de 1974, registou-se a contratação de professores do ensino regular, estando estes pouco atentos às características dos adultos, às suas necessidades e aos ritmos de aprendizagem. (PINTO; MATOS; ROTHES, 1998) Estes professores acabaram por assumir-se como agentes da institucionalização da educação. Centraram-se na transmissão de conhecimentos socialmente reconhecidos e legitimados, e fomentaram a conformidade social, procurando conceber e aplicar dispositivos educativos que adaptavam os indivíduos às condiçóes sociais de origem. (SANZ FERNÁNDEZ, 2006) 
Neste âmbito, muitos autores criticaram a "escolarização da educação de adultos" e o papel levado a cabo pelos educadores de adultos (PINTO, MATOS; ROTHES, 1998; LIMA, 2008, entre outros). Devido a opçóes pedagógicas de carácter mais escolar, diversas barreiras à participação dos adultos tornaram-se evidentes, culminando em níveis baixos de certificação de educação básica, não obstante o decréscimo da taxa de analfabetismo que passou para 11\%, em 1991, e para 9\%, em 2001. Apesar desta diminuição, o analfabetismo continua hoje ainda a ser um problema importante, mesmo que o valor relativo a 2011 se situe em 5,2\% (Disponível em: <http://www.ine.pt>), percentagem que ainda assim não é suficiente para tirar Portugal do último lugar da tabela a nível europeu (cf. 'New Cronos' do EUROSTAT, disponível em: <http://epp.eurostat.ec.europa.eu>).

Devido à existência de iniciativas da CEE, o Programa para o Desenvolvimento da Educação foi lançado em 1989 e mantido até 2006. Adicionalmente, significativas verbas foram concedidas à formação profissional (inicial e contínua) através de outros programas apoiados pelo Fundo Social Europeu. Mas, para além da formalização dos processos educativos e pedagógicos, as ações que decorreram dos referidos programas acrescentaram tendências de educação e formação para a competitividade (LIMA, 2008; GUIMARÃES, 2011) que, na última década, se tornaram mais expressivas. Neste âmbito, registou-se a realização de diversos cursos de educação e formação profissional inicial e contínua. A circunstância de ter o envolvimento do Ministério do Emprego, em particular o Instituto de Emprego e Formação Profissional, favoreceu a vocacionalização da educação (STOER; STOLEROFF; CORREIA, 1990) de adultos. Foi neste cenário que muitos formadores foram contratados. Sem formação de base específica no domínio da educação de adultos, estes recorreram aos saberes que detinham relativos aos modos de trabalho mais tradicionais na escola, procurando igualmente uma aproximação (curiosamente nem sempre conseguida) aos contextos de trabalho.

\section{A nova política de educação de adultos: tensões no trabalho dos educadores}

Em 1999, uma nova política de educação de adultos (BARROS, 2013b) - a educação e formação de adultos - foi adotada, enquanto se tornaram mais frequentes propostas de intervenção consentâneas com a educação e formação para a competitividade. Esta política baseou-se em discursos contraditórios, pessimistas na avaliação da situação educativa, mas otimistas nas finalidades estabelecidas. Estes discursos destacaram a necessidade de reposicionar Portugal no contexto da economia do conhecimento proposta pela UE. Tendo em vista combater o "deficit educativo" português, a educação e formação de adultos centrou-se na necessidade de reduzir o fosso existente entre o baixo nível de certificação escolar da população 
empregada, nível este detido por 75,6\% da população total, em 1995, com os valores apresentados por outros países, como a Alemanha (15,9\%) e a Dinamarca $(20,2 \%)$ (dados do EUROSTAT da época cit. por Melo; Matos; Silva, 2001). Ainda 1998, entre os 400.000 desempregados oficialmente registados, 250.000 não possuíam a escolaridade obrigatória. (MELO, 200, p. 103-104)

A preocupação relativa ao alinhamento das taxas de escolarização do nosso país com outras de países europeus centrais e nórdicos manteve-se mais tarde no quadro da adopção do Iniciativa Novas Oportunidades (INO), em 2005. Neste programa chamou-se a atenção para o facto de a média de anos de escolarização em Portugal, nesse mesmo ano, se situar nos 8,2 anos, enquanto que na Alemanha era de 13,4 anos e na Dinamarca de 13,6 anos (dados da OCDE em Education at a Glance de 2005 cit. em NO, 2005). Por isso, esta política procurou marcar profundas diferenças com a anterior que se centrava na educação de segunda oportunidade. Uma das ideias-chave assentava na criação de ofertas públicas nas quais racionais mais típicos da educação se articulassem com aqueles da formação, para assim criar inovação pedagógica e oportunidades de qualificação profissional. As ofertas públicas propostas, como no caso dos Cursos de Educação e Formação de Adultos (Cursos EFA) e do Reconhecimento, Validação e Certificação de Competências (RVCC), dirigiram-se a indivíduos maiores de 18 anos, que não possuíam certificação escolar do ensino básico ( $9^{\circ}$ ano de escolaridade) e, após 2007, do ensino secundário (12 ano de escolaridade), el ou sujeitos que não detinham qualificação profissional (de nível 1, 2, 3 ou 4, de acordo com as orientaçóes da UE).

Foram então definidas determinadas condiçóes que favoreceram a emergência de diversos perfis profissionais e a construção de um mercado de trabalho para os educadores de adultos. Este mercado procurou dar resposta a números expressivos de indivíduos que procuraram a educação e formação de adultos em resultado da adopção da INO, devido à ambiciosa finalidade política de envolver 1.000.000 de jovens e adultos. Se entre 2000-2005 estiveram no total inscritos 153.719 adultos neste processo e destes foram certificados 44.192, no período compreendido entre 2006-2010 estiveram no total inscritos 1.163.236 adultos e, destes, foram certificados 365.449. (CNE, 2011) Estando o valor dos adultos certificados longe da meta estabelecida, este programa traduziu-se, no entanto, num aumento dramático do acesso à educação e formação de adultos, nomeadamente da inscriçãao de mais de $10 \%$ da população portuguesa.

Frequentadas por grupos heterogéneos e integrando propostas de educação e formação que acentuaram a individualização dos processos, estas ofertas permitiram que, entre 2000 e 2010, 386.463 indivíduos fossem certificados, para o caso do RVCC (sobretudo de certificação escolar, dado que o processo de qualificação profissional através desta oferta foi residual), e 68.255 para os Cursos EFA. (ANQ, 2011) 
Em resultado, nesta última década, surgiram profissóes como a de técnico de diagnóstico e encaminhamento, profissional de reconhecimento e validação de competências, mediador e formador (que passaram a trabalhar a partir de referenciais de competências-chave específicos). A formação inicial ao nível da licenciatura passou a ser um requisito formal mínimo para a entrada nessas profissóes e (algumas) açóes de formação profissional contínua foram propostas a estes agentes, muitas destas por serviços estatais (COUCEIRO; PATROCÍNIO, 2002; ÁVILA, 2004) Adicionalmente, quando comparados com outros profissionais de áreas sociais e educativas, a complexificação do saber profissional (devido sobretudo à existência de regras instituídas) e a identificação de especificidades formais nas tarefas realizadas puderam ser observadas. Globalmente, estas circunstâncias originaram a diferenciação profissional e dos processos de educação e formação de adultos (comparativamente ao trabalho realizado pelos professores no ensino de segunda oportunidade, por exemplo) e implicaram um reconhecimento social mais alargado da educação de adultos e dos educadores.

Os educadores de adultos passaram então a assumir-se como promotores da certificação de "competências para competir", gestores de recursos humanos (LIMA, 2008; CAVACO, 2009), facilitadores de aprendizagens em função da sua rentabilidade económica e fomentadores de processos de "aprender a aprender" em contexto de trabalho. Neste sentido, surgiram como técnicos da aprendizagem ao longo da vida, que privilegiavam o conhecimento relacionado com o desenvolvimento do trabalho, que antecipavam problemas, tal como experimentavam soluçóes adaptativas que deviam ser levadas a cabo pelos indivíduos que aprendiam. (GUIMARÃES, 2009)

Neste âmbito, alguns estudos mostraram que os educadores de adultos contratados na última década, e que em 2010 totalizavam 11.611 elementos integrados nos Centros Novas Oportunidades, eram mais qualificados que os seus colegas que trabalhavam noutros domínios da educação de adultos, eram mais jovens e incluíam uma percentagem mais significativa de mulheres - a taxa de feminidade era de 73,9\% em 2010. (CNE, 2011) Devido à formaçáo inicial de base que possuíam (ao nível da licenciatura) e à inovadora estrutura das ofertas já mencionadas, estes educadores eram mais exigentes quanto à formação profissional contínua. No que se referia às associações profissionais, é verdade que se assistiu à criação destas entidades mais recentemente, como no caso da Associação Nacional de Profissionais de Educação e Formação de Adultos e da Associação Portuguesa de Educação e Formação de Adultos. Apesar desses esforços, pouco tempo se passou para que se registasse a consolidação dessas organizaçóes e a adoção de códigos de ética ou até para a afirmação da autonomia relativa (AFONSO, 2008) desses educadores, nomeadamente no que remete para a prestação de contas e a responsabilidade profissional. 
Confluindo este cenário ou não para isso, o certo é que a INO acabou por ser extinta em 2012, deixando um considerável número de educadores de adultos desempregados, que não encontrarão lugar, pelo menos no curto prazo, nos recém-criados 80 Centros para a Qualificação e o Ensino Profissional (Portaria no 135-A/2013, de 28 de março). É de notar que o início de atividade dos Centros tem sido marcado por uma reação de cariz meritocrático que tem levado a diversas alteraçóes no RVCC, como, por exemplo, a formalização do processo através da introdução de um teste para a avaliação de competências possuídas pelos adultos. Complementarmente, uma nova profissão surgiu - o técnico de orientação, reconhecimento e validação de competências - que substitui o técnico de diagnóstico e encaminhamento e o profissional de reconhecimento e validação de competências, desvirtuando desta forma alguns aspectos inovadores do processo, destacados, por exemplo, por Couceiro e Patrocínio (2002) e Àvila (2004).

\section{Percurso metodológico seguido}

Este artigo tem por base dois projetos de investigação qualitativa e interpretativa. Em ambos interessava saber, entre outros aspetos, como os educadores de adultos pensavam o seu trabalho, no quadro da intervenção de organizaçóes não-governamentais empenhadas na promoção de ofertas públicas existentes no quadro de "uma nova ordem educacional" estabelecida nacionalmente (pelas políticas públicas portuguesas) e supranacionalmente (no âmbito das orientaçóes e dos programas de apoio financeiro da UE). (FIELD, 2006; ANTUNES, 2008; BARROS, 2009, entre outros) Nestas pesquisas procurou-se cruzar dois paradigmas: i) o paradigma interpretativo e construtivista; e ii) o paradigma crítico. A discussão apresentada neste texto tem, pois, estes alicerces, retomando o cruzamento entre estes dois paradigmas, que visaram destacar a interdependência entre o sujeito e o objeto relativamente à importância atribuída às representaçóes da ação social, nomeadamente no quadro da complexa e interativa tarefa pedagógica de "ler o mundo”. (GUBA; LINCOLN, 1994)

Dois loci de recolha de dados foram selecionados: duas associações de desenvolvimento local promotoras de ofertas de educação e formação de adultos, designadamente Cursos EFA e RVCC, uma localizada no Norte e a outra no Sul de Portugal. Um destes projetos de investigação teve uma inspiração sociológica e envolveu entrevistas semi-diretivas a educadores de adultos dos Cursos EFA, desenvolvidos entre 2001 e 2005. O segundo projeto, de inspiração etnográfica, baseou-se em observação participante e entrevistas livres a educadores de adultos que trabalhavam no RVCC entre 2004 e 2005. A análise de conteúdo foi utilizada na interpretação dos dados colhidos através das entrevistas e das notas de campo. Por essa via, obteve-se frequências relativas a temas específicos. A análise de con- 
teúdo estrutural favoreceu a associação entre os temas identificados. (MAROY, 1997)

Assim, neste artigo procurou-se discutir tensôes com as quais os educadores de adultos inquiridos e observados no âmbito dos projetos de investigação mencionados se confrontavam.

\subsection{Os educadores de adultos e os cursos EFA: entre a reprodução e a reinterpretação de orientações oficiais}

Os cursos EFA constituíram-se numa aposta pedagógica inovadora (COUCEIRO; PATROCÍNIO, 2002; ÁVILA, 2004; CAVACO, 2009), porque estruturaram uma proposta diferente em termos de organização, conteúdos, modos de trabalho pedagógico e avaliação. Integraram componentes de educação não formal e informal que afastaram estes Cursos de outras ofertas de carácter mais formalizado e escolar, como, por exemplo, os métodos de trabalho, preferencialmente ativos, os materiais pedagógicos e a organização modular. Ainda, ao assentarem em percursos educativos e formativos que podiam ser de longa duração, estas ofertas encerraram em si possibilidades de inserção social e económica. Neste âmbito, destacava-se a combinação das componentes de educação de base e de formação profissional, designadamente nos Cursos que atribuíam certificação escolar e qualificação profissional. Em paralelo, estes Cursos assentaram numa abordagem por competências, localizadas e contextualizadas na vida (social, profissional e pessoal) dos adultos. De resto, a construção do currículo destes Cursos baseou-se em Referenciais de Competências-Chave (ALONSO et al., 2000; GOMES, 2006), que contribuíam para a resolução de problemas (mais ou menos complexos) com os quais os indivíduos se confrontavam nos seus quotidianos. Estes Cursos incluíam também um módulo sobre aprender com autonomia, no caso dos Cursos equivalentes ao ensino básico, e, após 2007, um outro que propunha a construção de um portefólio reflexivo de aprendizagem, no caso dos Cursos equivalentes ao ensino secundário. Estes módulos procuravam a inclusão dos adultos nos grupos em educação e formação e o relacionamento interpessoal entre os diversos atores (adultos e educadores), bem como o desenvolvimento de aprendizagens mais consciencializadas e autónomas. Deve-se notar ainda que estes Cursos integravam a abordagem de Temas de Vida, definidos a partir do conhecimento que os educadores possuíam dos formandos. Esta opção visava valorizar e problematizar as biografias dos adultos, constituindo-se em momentos nos quais se cruzavam áreas, competências e componentes da educação e formação. Esta conjugação de aspectos favoreceu a atribuição de novos papéis aos educadores de adultos. Como referiu uma entrevistada: 
Porque eu [enquanto educadora de adultos] não sou tanto de impor, sou mais de fazer com que os adultos façam uma descoberta. Acho que é mais proveitoso ser o adulto a descobrir coisas, a aperceber-se das coisas, a ver que são capazes de fazer as coisas. Não é o formador estar ali a impor matérias, como acontece no ensino, que leva os adultos a serem críticos. (...) E porque é que faço isto? Como eles são pessoas com baixa autoestima, é preciso fazê-los acreditar de que são capazes. [E(FR)5]

Estes novos papéis deviam-se, por exemplo, à realização de tarefas que se prendiam com a informação, o aconselhamento, a orientação, a mediação, a articulação de conhecimentos e saberes etc. Caracterizavam-se pelo facto de estarem ligados a tarefas que muitos outros agentes executavam. Esta situação parecia propiciar o trabalho em equipa e a aprendizagem colaborativa, a partilha de saberes, o desenvolvimento de conhecimentos contextualizados, umas vezes mais reflexivos que outras. (COUCEIRO; PATROCÍNIO, 2002; ÁVILA, 2004)

Todavia, os educadores de adultos inquiridos afirmaram que era o carácter inovador desta oferta, sendo aqui destacadas as dimensóes não escolar, não formal e informal das iniciativas, que levantava diversos problemas, em particular aos menos experientes. Não existindo formação graduada inicial específica e sendo recente a organização de açóes de formação contínua (que incidiam em particular sobre aspetos processuais) (GUIMARÁES, 2009), muitos agiam de acordo com a sua experiência, adquirida, por exemplo, no âmbito de açôes de formação contínua ou quando eles próprios eram alunos. Por esta razão, defendiam a necessidade de participar em momentos que favorecessem a reflexão e a partilha de saberes sobre as práticas profissionais que desenvolviam. Como afirmou uma inquirida:

Foi complicado. Eu caí de paraquedas. Eu recordo-me que comecei a trabalhar no dia 11 de Setembro de 2001 e o primeiro Curso arrancou a 17. Sem qualquer tipo de formação prévia. Portanto, o pouco que eu aprendi acerca dos Cursos EFA foi através da leitura, discussão com a colega que já cá estava havia mais tempo, mas, sendo ela assistente social, também não tinha grande conhecimento. Foi um bocado complicado. Isto de facto era uma coisa completamente inovadora, completamente diferente. [...]. Os dois primeiros anos de trabalho foram muito mais aprender pela experiência. Foi de facto quando tentámos aprender todos em conjunto. [E(M)1]

Devido a estas dificuldades, muitos educadores tendiam a realizar tarefas marcadamente normativas e prescritivas que envolviam uma diversidade de aspetos definidos por serviços externos ao contexto de trabalho. Exemplos destes serviços contemplavam as agências estatais responsáveis pela dinamização 
da política pública de educação e formação de adultos (num primeiro momento, após 1999, a Agência Nacional de Educação e Formação de Adultos, depois a Direcçáo-Geral de Formação Vocacional, entre 2002 e 2007; após 2007, a Agência Nacional para a Qualificação e, desde 2011, a Agência Nacional para a Qualificação e Ensino Profissional), tal como aqueles que atribuíam apoios para desenvolver diversas iniciativas, como as instituiçóes de financiamento, ou como o Instituto de Emprego e Formação Profissional que monitorizava a componente de formação profissional. Verificava-se uma tendência para a regulação do trabalho realizado pelos educadores de adultos. Em decorrência, a reprodução de práticas sugeridas pelas agências atrás mencionadas ocorria, mesmo que em certos momentos se assistisse à reinterpretação de orientaçóes, como destacou Loureiro (2009), que, contudo, raramente ia para lá da dimensão pedagógica dos Cursos. (GUIMARÁES, 2011)

\subsection{O RVCC: entre a ambição de suscitar metaconhecimento biograficamente ancorado e a urgência de reconhecer e certificar competências}

A pesquisa sobre o RVCC também permitiu desocultar diversas tensões nos contextos educacionais. Foram recolhidos dados que evidenciaram várias ambivalências sobretudo resultantes da relação contraditória entre as prioridades políticas (nacionais e supranacionais) da nova política de educação e formação de adultos cujo racional foi, como vimos, o de uma educação e formação para a competitividade. $\mathrm{Na}$ verdade, o tempo de ação desta política pública era de curto prazo, pois os resultados (relativos à certificação e qualificação de adultos) deviam ser obtidos muito rapidamente, de acordo com as orientaçóes da agência estatal responsável. De facto, a lógica de médio prazo da prática pedagógica do reconhecimento de adquiridos experienciais visava resultados, em termos de auto-reconhecimento (pelo próprio) e de hetero-reconhecimento (pelo Outro), que exigiam outro tipo de prioridades político-educativas (subnacionais), desde logo com uma conceção de tempo vincadamente lento, capaz de mostrar abertura para ritmos que poderiam diferir de caso para caso e de contexto para contexto. Ou seja, uma das mais significativas tensões observadas na oferta de RVCC ao nível das prioridades políticas foi a resultante da colisão entre o ritmo acelerado e o compasso uniforme impostos sobre o local pela agenda política nacional e europeia (consubstanciado nas exigências dos financiamentos concedidos) e o ritmo lento e o compasso diferenciado exigidos no âmbito da modalidade educativa do reconhecimento de adquiridos experienciais. (BARROS, 2011)

Deste facto resultaram soluções técnico-processuais desenvolvidas localmente pelos educadores de adultos, especialmente pelos profissionais de reconhecimento e validação de competências (diretamente implicados ao longo de 
todo o processo) que dotaram de uma tonalidade híbrida as dimensóes educativas e pedagógicas observadas. Assim, por exemplo, foi admitido pelos educadores que os aspetos mais ambiciosos ao nível educacional e de metacognição traçados inicialmente por si próprios no âmbito do trabalho de balanço de competências e de elaboração do portefólio individual, visando o reconhecimento de adquiridos experienciais, se iam tornando menos importantes face à necessidade de cumprir as metas estatísticas impostas e certificar mais pessoas. Segundo as linhas programáticas, as metas definidas para o período 2005-2010 eram ambiciosas, dado que o objetivo passava por alcançar a certificação de mais de 650.000 adultos (305.000 ao nível básico e 345.000 ao nível secundário). (ANQ, 2011) Ou seja, no contexto estudado, a intervenção educativa programada inicialmente com metodologias ativas de ambição crítica acabou substituída pela capacidade organizativa, pela decisão estratégica face ao planeamento mais eficaz da duração do processo, visando identificar mais rapidamente as competências-chave dos adultos porque, como afirmou uma entrevistada: "É necessário fazer muitos certificados para o Centro continuar aberto no próximo ano... [RE(C)1].”

Este foi um dilema central que a equipa de educadores estudada teve, por força e peso da regulação central, de aprender a gerir de modo pragmático, articulando estratégias de trabalho capazes de garantir a conclusão, em tempo útil, dos portefólios individuais de cada adulto, essenciais na hora de validar as competências e garantir a certificação. No entanto, tratar-se-ia de orientação nas prioridades político-educacionais crítica e não deixaram de surgir certos questionamentos, como estes:

Como cumprir as metas, mantendo o nível de exigência?" $[\mathrm{RO}(\mathrm{D}) 6]$.

Entendemos isto cada vez mais como um produto [... ] poucos adultos ficaram com uma visão clarificada sobre a sua vida e com as suas competências críticas ampliadas, e porquê? Porque estamos preocupados com as metas [...] [RO D)7].

Tal como nos Cursos EFA, o RVCC baseava-se numa abordagem educativa e pedagógica distinta da formal. Neste caso pretendia-se identificar o que já se sabia em lugar de transmitir conteúdos predefinidos para todos os que acediam a ofertas educacionais. Por este motivo, a natureza metodológica do balanço de competências foi identificada como uma das principais dificuldades enfrentadas desde o início pelos educadores de adultos, especialmente os profissionais de reconhecimento e validação de competências, como expressou esta entrevistada:

Quando comecei aqui nem sequer tinha muito claro o que era uma entrevista biográfica, ou um balanço de competências [... ] mas depois com a prática uns dos outros vamos aprendendo. E 
há também as orientações técnicas [feitas em Lisboa pela agência estatal responsável] que esclarecem muito como é que se devem fazer as coisas [... ] portanto, depois de perceber como é, basicamente é só seguir os procedimentos. A maior dificuldade que sinto hoje é que há muitos papéis a preencher e organizar para cada um dos adultos e isso é esmagador [... ] mas representa grande parte do meu trabalho. [RO(S)25].

Como já foi referido, em Portugal, estes educadores de adultos não tinham formação de base específica em educação e, em muitos casos, não estavam a par da história nacional do sector, nem do património internacional de conhecimento existente, e tampouco dominavam as especificidades metodológicas próprias da educação de adultos. Este facto facilitou a adoção quotidiana do que se tornava mais operativo e funcional às metas estabelecidas, sobretudo atendendo a que estes educadores trabalhavam com uma população adulta com percursos escolares curtos, muitos destes marcados pelo absentismo, insucesso e abandono escolar precoce. Os resultados da pesquisa revelaram que havia uma "pedagogia híbrida" (DIONÍSIO, 2007) na prática profissional dos educadores de adultos, que obrigou a uma adaptação (e redução) progressiva dos pressupostos metodológicos próprios do balanço de competências e das abordagens biográficas face às exigências externas. A realidade quotidiana destes contextos e a pressão estatística na obtenção de (rápidos) resultados de certificação era evidente, mesmo que o grau de cumprimento dos objetivos estabelecidos para a inscrição de adultos no processo fosse mais facilmente atingível que os valores relativos à certificação. Esta pressão, que se traduzia na ameaça da diminuição ou suspensão de financiamento para os Centros que não atingissem os objetivos definidos, tinha repercussóes no trabalho quotidiano dos educadores de adultos. Esta circunstância permitiu-nos questionar se as respostas encontradas, à data e face a estas tensóes, não deram azo a uma deturpação do próprio capital histórico da modalidade educativa do reconhecimento de adquiridos experienciais. (BARROS, 2011) Note-se que, entre 2007 e 2010, a duração dos processos de nível básico oscilava entre 6 e 7 meses e os de nível secundário entre 5 e 10 meses (CNE, 2011), o que revelava a variabilidade do tempo dedicado a este processo e as diferenças nos modos de trabalho educativo e pedagógico assumidos pelos agentes.

Esta hipótese emergiu porque se sabe que o reconhecimento dos adquiridos experienciais pode apelar a um modo de "trabalho pedagógico apropriativo" (LESNE, 1984), ou seja, assente na real possibilidade de explorar uma relação pedagógica de tipo mais horizontal, composta sobretudo por metodologias ativas capazes de convocar um trabalho mais emancipatório para os educandos e mais problematizador e engajado para os educadores. Seria então de esperar que esta oferta estivesse mais ancorada no âmbito do modelo de políticas de educação crítica e se caracterizasse por um tempo mais longo. 
Mas os dados mostraram que, no geral, o processo era conduzido de modo pragmático e tecnicizado, reproduzindo-se práticas muito implicadas na valorização (apenas) das competências necessárias para que a população adulta ativa (que no modelo português era a única com acesso previsto a esta modalidade) se tornasse possuidora de uma certificação equivalente à escolaridade básica. Neste aspeto, a realidade revelou que estava a ser operacionalizado localmente um processo de reconhecimento de adquiridos experienciais muito eficaz por ser capaz de resolver (rapidamente) o problema político da baixa qualificação da população adulta ativa portuguesa. Assim, o trabalho, realizado pelos educadores de adultos, seguia de perto, sem grande debate, pressupostos transversais que visavam incutir uma postura de flexibilidade, senão mesmo de responsabilização pela obrigatoriedade de auto-adequação dos conhecimentos dos adultos, por exemplo, às necessidades de calendarização do processo, ou das unidades e critérios de evidências dos referenciais, face aos quais, se procurava reunir um conjunto de provas documentais que ilustrassem competências e aprendizagens experienciais oriundas do quotidiano. Tratava-se de pressupostos, de resto, bem característicos da abordagem da educação e formação para a competitividade.

\section{Considerações finais}

Foi no contexto da nova política de educação e formação de adultos que novas profissóes foram criadas. Estas abrangiam novas áreas de intervenção educativa e formativa. Este novo mercado de trabalho revelou-se atraente para recém-licenciados que, não tendo formação inicial específica, se empenharam num trabalho que foram descobrindo, umas vezes de modo mais fácil, outras enfrentando dúvidas e dificuldades. De resto, a perceção quer de educadores de adultos, quer dos adultos sobre o envolvimento nas ofertas em análise foi positiva, como evidenciaram Valente, Carvalho e Carvalho (2011). Todavia, estes educadores de adultos nunca se reconheceram enquanto tal e gozaram de pouco reconhecimento social, dado que as políticas de educação de adultos foram marcadas neste país pela intermitência e descontinuidade. Talvez devido a estas razôes, estes educadores acabam por assumir-se como gestores de recursos humanos e técnicos da aprendizagem ao longo da vida (e não como ativistas da educação crítica).

Em resultado, num quadro político e educativo ambíguo, até ao final da primeira década deste século, estes educadores de adultos encontraram-se numa encruzilhada. Se, por um lado, durante o período estudado, ainda formulavam discursos sobre a educação de adultos de cariz humanista, em particular quando valorizavam o papel dos adultos na construção dos seus percursos de educação e formação, por outro lado, sobretudo durante a vigência da INO (2005-2012), encontraram-se pressionados por finalidades economicistas, nomeadamente aque- 
las que apelavam à educação e formação para a competitividade e ao cumprimento de objetivos de certificação, assim como por outras de cariz técnico que retiraram a dimensão política ao trabalho educativo levado a cabo.

Entre discursos mais progressistas e práticas mais consentâneas com políticas sociais restritivas de emprego, estes educadores encontravam-se cada vez mais afastados das raízes históricas mais críticas da educação de adultos. Nesta encruzilhada, e no momento de uma acentuada transição que se vive no setor desde 2012, como afirmou Loureiro (2012), novas pesquisas se justificam para problematizar o que é que estes indivíduos perderam e o que é ganharam, bem como qual o significado das perdas e dos ganhos obtidos para educadores que estavam longe de possuir uma profissão (ou, atualmente, um emprego) e que, paradoxalmente, estavam igualmente cada vez mais longe de manifestar um forte comprometimento com a transformação social e a promoção da emancipação social.

\section{Referências}

AGÊNCIA NACIONAL PARA A QUALIFICAÇÃO (ANQ). Linhas Orientadoras para o Futuro da Iniciativa Novas Oportunidades. Lisboa: Agência Nacional para a Qualificação, 2011.

AFONSO, A. J. Políticas educativas contemporâneas: dilemas e desafios. In: CUNHA, N. (Coord.). Pedagogia e educação em Portugal séculos XX e XXI. Famalicão: Museu Bernardino Machado, 2008, p. 59-80.

ALONSO, L. et al. Educação e formação de adultos. Referencial de competências-chave. Lisboa: ANEFA/Ministério do Trabalho e da Solidariedade/Ministério da Educação, 2000.

ANTUNES, F. A nova ordem educacional. Espaço europeu de educação e aprendizagem ao longo da vida. Coimbra: Almedina, 2008.

ÁVILA, P. Relatório nacional de avaliação. Cursos de educação e formação de adultos 2002/2003. Lisboa: Direcção-Geral de Formação Vocacional, 2004.

BARROS, R. Políticas para a educaçáo de adultos em Portugal - A governaçáo pluriescalar da "nova educaçáo e formaçáo de adultos" (1996-2006). 2009. Tese (Doutorado em Educação). Instituto de Educação. Universidade do Minho, Braga.

. A criação do reconhecimento de adquiridos experienciais (RVCC) em Portugal - Uma etnografia crítica em educação de adultos. Lisboa: Chiado Editora, 2011.

CAVACO, C. Adultos pouco escolarizados - Políticas e práticas de formação. Lisboa: Educa e UI \& DCE, 2009.

COUCEIRO, M. L.; PATROCÍNIO, T. Cursos de educação e formação de adultos "em observação" 2000/2001. Relatório nacional. Lisboa: ANEFA, 2002. 
CONSELHO NACIONAL DE EDUCAÇÃO (CNE). Estado da Educação 2011 - A Qualificação dos Portugueses. Conselho Nacional de Educação, 2011.

DIONÍSIO, M. L. Estudo III - 'O conjunto é que faz com que as coisas funcionem'. A pedagogia híbrida dos Cursos EFA. In: CASTRO, R. V. (Org.) et al. Os Cursos EFA numa associação local. Contexto organizacional, orientaçóes e práticas de educaçâo de adultos. Vila Verde: ATAHCA/UEA da Universidade do Minho, 2007, p. 82-95.

FIELD, J. Lifelong learning and the educational order. Stoke on Trent: Trentham Books, 2006.

GOMES, M. C. (Coord.). Referencial de competências-chave para a educação e formação de adultos - Nivel secundário. Lisboa: Direcção-Geral de Formação Vocacional, 2006.

GUBA, E. G.; LINCOLN, Y. Competing paradigms in qualitative research. In: DENZIN, N. K.; LINCOLN, Y. (Eds.). Handbook of qualitative research. USA: Sage, 1994, p. $105-117$.

GUIMARÁES, P. Reflections on the professionalisation process of adult educators on the frame of public policies in Portugal. European Journal of Education, v. 44, n. 2, 2009, p. 205-219.

. Políticas de educação de adultos em Portugal (1999-2006). A emergência da educação e formação para a competitividade. Braga: Cied/Universidade do Minho, 2011.

LESNE, M. Trabalho pedagógico e formação de adultos - Elementos de análise. Lisboa: Fundação Calouste Gulbenkian, 1994.

LIMA, L. C. A educaçâo de adultos em Portugal (1974-2004). In: CANÁRIO R.; CABRITO, B. (Orgs.). Educação e formação de adultos. Mutaçôes e convergências. Lisboa: Educa, 2008, p. 31-60.

LOUREIRO, A. O trabalho técnico-intelectual em educação de adultos: contribuição etnossociológica para a compreensão de uma ocupação educativa. Cascais: Sururu, 2009.

. "Novos" territórios e agentes educativos em sociologia da educação: o caso da educação de adultos. Revista Lusófona de Educação, v. 20, 2012, p. 123-139.

MAROY, C. A Análise qualitativa de Entrevistas. In: ALBARELLO, L. et al. Práticas e métodos de investigação em ciências sociais. Lisboa: Gradiva, 1997, p. 117-155.

MELO, A. Uma Nova Vontade Política de Relançar a Educação e Formação de Adultos? In: TEODORA (Org.). Educar, Promover, Emancipar - os contributos de Paulo Freire e Rui Grácio para uma Pedagogia Emancipatória. Lisboa: Ediçôes Universitárias Lusófonas, 2001, p. 101-120.

MELO, A.; BENAVENTE, A. Educação Popular em Portugal (1974-1976). Lisboa: Livros Horizonte, 1978.

MELO, A. (Coord.); MATOS, L.; SILVA, O. S. S@ber+. Programa para o desenvolvimento e expansão da educação e formação de adultos (1999-2006). Lisboa: Agência Nacional de Educação e Formação de Adultos, 2001. 
MINISTÉRIO DA EDUCAÇÃO. Trabalhos preparatórios para o Plano Nacional de Alfabetização e Educação de Base dos Adultos (PNAEBA). Relatório síntese. Lisboa: Ministério da Educação, 1979.

NOVAS OPORTUNIDADES (NO), 2005 Disponível em: <http://www.novasoportunidades.gov.pt/np4/9.html>. Acesso em 16 de julho de 2014.

PINTO, M.; MATOS, L.; ROTHES, L. Relatório do Estudo de Avaliaçâo do Ensino Recorrente. Lisboa: Ministério da Educação/Secretaria de Estado da Educação e Inovação, 1998.

ROTHES, L. A formação dos educadores de adultos em Portugal. Trajectos e tendências. Forum, n. 34, 2003, p. 35-62.

SANZ FERNÁNDEZ, F. As raízes históricas dos modelos actuais de educação de pessoas adultas. Lisboa: Educa/Unidade de Ciências da Educação, 2006.

STOER, S. R.; STOLEROFF, A.; CORREIA, J. A. O novo vocacionalismo na política educativa em Portugal e a reconstrução da lógica da acumulação. Revista Crítica de Ciências Sociais, n. 29, 1990, p. 11-53.

VALENTE, C., CARVAlHO, L.; CARVALHO, A. Bringing lifelong learning to low-skilled adults: the New Opportunities Initiative. In: CARNEIRO, R. (Dir.). Accreditation of prior learning as a lever for lifelong learning: lessons learnt from the New Opportunities Initiative, Portugal. Braga: UNESCO/MENON/CEPCEP, p. 145-182.

Recebido em 09 de janeiro de 2013.

Aprovado em 24 de outubro de 2014.

DOI: http://dx.doi.org/10.1590/ES0101-73302015109444 